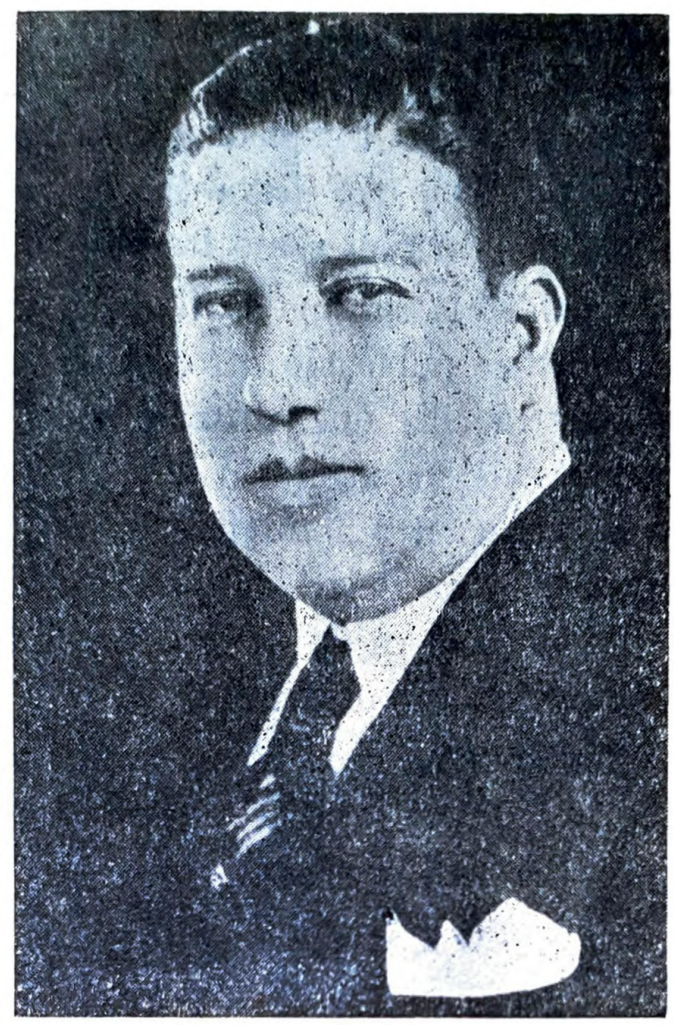

\title{
ENRIQUE A. CERVANTES
}

El día $22 \mathrm{dcl}$ pasado mes de marzo falleció en la ciudad de México el Ingeniero Enrique A. Cervantes. El Instituto de Investigaciones Estéticas rinde homenaje al lāborioso trabajador en el campo de nuestra historia artística. Enrique Cervantes supo unir, a las dotes del crítico que sólo afirma lo que encuentra fundamentado en el documento fehaciente, es decir, el rigor histórico a que todos aspiramos, el buen gusto, el sentido de lo bello en sí mismo, porque era en el fondo un artista. Allí están para comprobarlo sus álbumes de fotografías en que captó en un momento dado los aspectos más entrañables de nuestras ciudades-museos: Tasco, Puebla, Querétaro, Morelia, Oaxaca, Mérida, Guanajuato. Sus monografías ofrecen ese doble aspecto documental-artístico. Infatigable hurgador de archivos encontró informaciones de primera mano acerca de joyas del arte colonial como el retablo principal de Santo Domingo de Puebla, la sillería del coro de la Catedral Metropolitana y otros. 
$\mathrm{Su}$ obra capital, indispensable para quien quiera tratar el terna, es el libro Loza blanca y azulejo de Puebla (2 vols. México, 1939), que 110 sólo es lo 111 ás completo que se ha escrito acerca de la cerrimica poblana, sillo que desvanece de modo irrefutable tradicionales errores que corrín como buenos.

Con10 es e libro, dada la enorme canticlad de documentos que pudo reunir, debió haber publicado otros, si la vida lo hubiera permitido. Sufrióo la tragedia que acosa a tanto trabajador del espíritu: las urgencias del momento lo obligaron a ocuparse en asuntos ajenos a su vocación y aptitudes, asuntos que cualquiera habría podido ejecutar, para dejar abandonados sus papeles, sus fichas, sus fotografías en el cajón del escritorio de una oficina; fué, en fin, un esclavo de la burocracia.

Deseo consagrar aquí un recuerdo al amigo y al compañero de trabajo. Uno más que nos precede en la excursión definitiva.

M. T.

\section{BIBLIOGRAFIA}

1926. Monografia del Mitnicipio en Tehuacín, Estado de Puebla. Memorias de la Sociedad Antonio Alzate. T. 45.

1928. Contrato para el retablo mayor de Santo Dominȩo de Puebla. Revista Mexicana de Estudios Históricos. T. II, núm. 1.

1932. Hierros de Oaxaca.

1933. Herreros 31. Forjadores Pablanos.

1933. Nómina de laceros poblanos durante el período virreinal.

1936. Catedral Metropolitana. Sillería del Coro.

1939. Loza blanca y azulejo de Puebla. (Dos tomos.)

1942. Visita a la Colonia del Nuevo Sontander, hecha por el Licenciado don Luis Nepomuceno Gómez, el año de 1770. Introducción.-

1938. Bosquejo del desarrollo de la Ciudad de Puebla de los Angeles.

1942. Bosquejo del desarrollo de la Ciudad de Guanajuato.

1945. Bosquejo del desarrollo de la Ciudod de Mérida. 
DOI: https://doi.org/10.22201/iie.18703062e.1953.21.556

1928. Filfec.

1929. Cuernaestc(J.

1930. Morelia.

1931. Tepic.

1932. Oaxaca.

1933. Puebla de los Angeles.

1934. حantiago de Querétaro.

10.37. Guanajuato

1942. Mérida.

1933. Plano de la Ciudad de Oaxaca.

1937. Plano de la Villa de los Cinco Señores del Nuevo Santander, hoy Iiménes, del Estado de Tomauiipas.

1942. Ptano de la Ciiidad de Jiquilpan de luórez, l'Alfich.

1949. Testamento de Sor Luana Inés de la Critz. 